Research Journal of Medical Sciences 4 (3): 187-194, 2010

ISSN: $1815-9346$

(C) Medwell Journals, 2010

\title{
Applications of Forensic Dentistry: Part-II
}

\author{
C. Stavrianos, A. Kokkas, A. Eliades and E. Andreopoulos \\ Department of Endodontology, Forensic Dentistry Dental School, \\ Aristotle University, Thessaloniki-54124, Greece
}

\begin{abstract}
The purpose of the study is to review and present the aims and the applications of Forensic dentistry. Bite marks are usually seen in cases involving sexual assault, murder, child abuse and can be a major factor in leading to a conviction. Bite marks can be found anywhere on a body particularly on soft and fleshy tissue such as the stomach or buttocks. In addition, bite marks can be found on objects present at the scene of the crime. However, there are two types of family violence, the child abuse and the adult violence in the house or marital abuse or elder abuse. These types of family violence can happen to any of environment. Child abuse, intimate partner abuse and elder abuse victims often have signs of injury or bite marks that are readily visible to dentists. Dentists have a moral and legal obligation to recognize and report suspected abuse. It is important to realize that all dentists have a unique opportunity and ethical obligation to assist in the struggle against child abuse. The dentists are likely to be in contact with these individuals who have been exposed to this kind of violence. The dental team that is alert to the fact that many elderly or vulnerable person or child are abused and that many of these abused individuals have injuries to the head and around the mouth may be able to identify an abused person and institute steps that might save someone's life. Finally, the important role of forensic odontology in archaeological research is reported.
\end{abstract}

Key words: Forensic dentistry, bite marks, family violence, child/elder abuse, marital abuse, archaeological research, responsibility

\section{INTRODUCTION}

Forensic dentistry is the branch of dentistry that deals with the legal aspects of professional dental practices and treatment with particular emphasis on the use of dental records to identify victims of crimes or accidents. One sector of forensic odontology is the analysis of bite marks. Dental professionals have a major role to play in keeping accurate dental records and providing all necessary information so that legal authorities may recognize malpractice, negligence, fraud or abuse and identify unknown humans (Avon, 2004).

Additionally, traces of saliva deposited during biting can be recovered to acquire DNA evidence and this can be analyzed to determine who contributed this biological evidence. If dentists are aware of the various methods to collect and preserve bitemark evidence from victims and suspects it may be possible for them to assist the justice system to identify and prosecute violent offenders (Sweet et al., 1996). Especially, the dental expert or forensic odontologist has a crucial role in matching the bite mark impressions on a victim to the tooth structure of suspects. The aim of the study is to describe an objective analysis technique which could be used when confronted with a bite mark case. However, the important role of forensic odontology in recognition of child or elder abuse is reported because dentists have a moral and legal obligation to recognize and report suspected abuse. All dentists have a unique opportunity and ethical obligation to assist in the struggle against child or elder abuse. Finally, the significant role of forensic odontology in archaeological research is reported.

Bite marks: From the ancient years the dentition was used in various ways (eating, personal defense, practice of ratification of documents). The human denture includes exceptionally individualized data. Their importance is proportional with these of the fingerprints. Dental tooth prints attribute individualized information about the teeth of the dentition. The first bite mark case in the United States was the famous Salem Witch Trials in 1692. Rev. Burroughs who convicted and hanged used to bite his victims. During the trial his bite marks and of other people were compared to the victim's marks.

The judges readily accepted the bite marks as evidence (Barsley, 1993; Rothwell, 1995; Vale, 1996; Herschaft et al., 2006; Silver and Souviron, 2009). Probably, the most famous incident where human bite mark evidence led to a conviction was the case of the

Corresponding Author: Christos Stavrianos, Department of Endodontology (Forensic Dentistry) Dental School, Aristotle University, Thessaloniki, Greece 
notorious serial killer and Ted Bundy. Nobody really knows how many people Bundy killed between 1973 and 1978 but he was finally tied to the murder of Lisa Levy who he attacked in the Chi Omega Sonority house of Tallahassee's Florida State University, through bites that he inflicted on her body.

Forensic bite mark analysis revealed Bundy's highly irregular teeth left the impressions. Forensic Bite Mark Analysis-How Reliable is the Evidence? Another case concerns Edmund Burke, police arrested Burke in 1998 for the murder of a 75 years old woman in Walpole, Mass. The woman was strangled, beaten and stabbed and there was a bite mark on her left breast. The probable cause for Burke's arrest was the findings of forensic odontologist Dr. Lowell Levine who was a prosecution witness in Prade's case. The killer later was identified by matching the DNA derived from the bite mark to a DNA profile in a national database.

According to the American Board of Forensic Odontology, the human cutaneous bite mark is defined as follows: an injury in skin caused by contacting teeth (with or without the lips or tongue) which shows the representational pattern of the oral structures. The bite mark can be caused either by human or by animals.

Bite marks are usually seen in cases involving sexual assault, murder, child abuse and can be a major factor in leading to a conviction. Bite marks can be found anywhere on a body particularly on soft, fleshy tissue such as the stomach or buttocks. In addition, bite marks can be found on objects present at the scene of the crime (Furness, 1981; Rothwell, 1995; Stimpson and Mertz, 1997).

\section{MATERIALS AND METHODS}

Types of bite marks: A representative human bite is described as an elliptical or circular injury that records the specific characteristics of the teeth. The injury may be shaped like a doughnut with characteristics recorded around the perimeter of the mark. Alternatively, it may be composed of two U-shaped arches that are separated at their bases by an open space (Bowers and Bell, 1995). These types of bite marks can be identified:

- Hemorrhage-small bleeding spot

- Abrasion-undamaging mark o skin

- Contusion-ruptured blood vessel, bruise

- Laceration-punctured or torn skin

- Incision-neat puncture of skin

- Avulsion-removal of skin

- Artifact-bitten-off piece of body (Stavrianos and Metska, 2002)

These types can be classified by four degrees of impression:
- Clearly defined-significant pressure

- Obviously defined-first degree pressure

- Quite noticeable-violent pressure

- Lacerated-skin violently torn from body

The marks left by the teeth in a person may be used to identify an individual. The characteristics of human bites are superficial abrasion and/or sub-surface hemorrhage looking like an arch. They are caused by the incisors, canines and premolars. The abrasions and/or hemorrhage caused by the canine are in a shape of points.

Contusions are the most common type of bite mark and incisions offer the best three-dimensional image of the teeth. It can also be determined from the type of bleeding beneath the skin whether the victim was alive or dead at the time the bite mark was delivered (Furness, 1981; Rothwell, 1995; Sweet et al., 1996; Sweet and Hildebrand, 1999; Stavrianos and Metska, 2002). Bitemarks can be found in:

- Assault in children and adults

- Homicides

- Sexual crimes

- Dental tooth prints in inanimate objects in the space of crime like cheese, meat, chewing gums

When there are bitemarks, the collection of evidence, the maintenance, the analysis and the comparison must be made from authorized authorities and well trained health providers. A forensic dentist must record, impress (Fig. 1) and photograph the bitemarks with great length. The saliva which has been deposited on the skin during biting or sucking should collect and analyzed through elements from the antigens of saliva. The analysis of DNA can

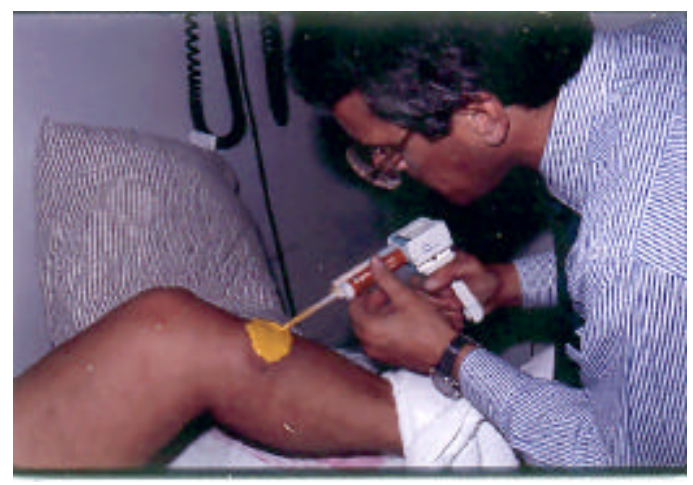

Fig. 1: Dr. D. Sweet investigations a case of dental (bite) marks. Impressions should be taken of the surface of the bitemark whenever it appears that this may provide useful information 
provide a genetic profile for the suspect and a genetic database. The recorded data include the general or the individualized characteristics of the dentition of perpetrator, the dimensions of teeth and the distance between incisors. The materials which usually are used to impress bite marks are the vinyl polysiloxane, polyether, plastic or dental acrylic (Sweet et al., 1996; Stimpson and Mertz, 1997; Sweet and Hildebrand, 1999; Silver and Souviron, 2009). Bitemarks could be found in dead or alive victims and to the body of the perpetrator.

There is a fundamental rank for the forensic dentist which says that a suspect bitemark is considered real up to proof the contrary. The forensic odontologist will also be able to recognise and record bite marks in other substances such as food stuffs (apples, cheese, chocolate), leather (key rings and belts) and wood (pencils) (Rothwell, 1995; Sweet, 1996). Using the same digital imaging techniques as used for bite mark analysis, the forensic odontologist can make similar comparisons between offensive weapons and injuries seen on victims.

\section{RESULTS AND DISCUSSION}

Bite marks analysis is a controversial issue: Although, bite mark analysis has been used in legal proceedings since 1870 , it remains a controversial topic due to a variety of factors. Skin is not a good medium for dental impressions; it is liable to have a number of irregularities present before the imprint that could cause distortion. Also, bite marks can be altered through stretching, movement or a changing environment during and after the actual bite. Furthermore, the level of distortion tends to increase after the bite mark was made (Pretty and Sweet, 2001). Bite mark analysis is also controversial because dental profiles are subject to change.

The loss of teeth or the alteration of arch configuration through a variety of procedures is common in human populations (Dorion, 2005). Finally, the methodology behind analyzing bite mark is extremely variable because it depends upon the preference of the specific odontologist. The lack of interpretation with any bite mark evidence (Dorion, 2005; Pretty and Sweet, 2001).

Domestic violence: Forensic odontology has also two areas of utilization: diagnostic and therapeutic examination and evaluation of injuries to jaws, teeth and oral soft tissues and identification, examination and evaluation of bite marks which occur with some frequency in sexual assaults, child or elder abuse cases and in personal defense situations (Stimpson and Mertz, 1997).

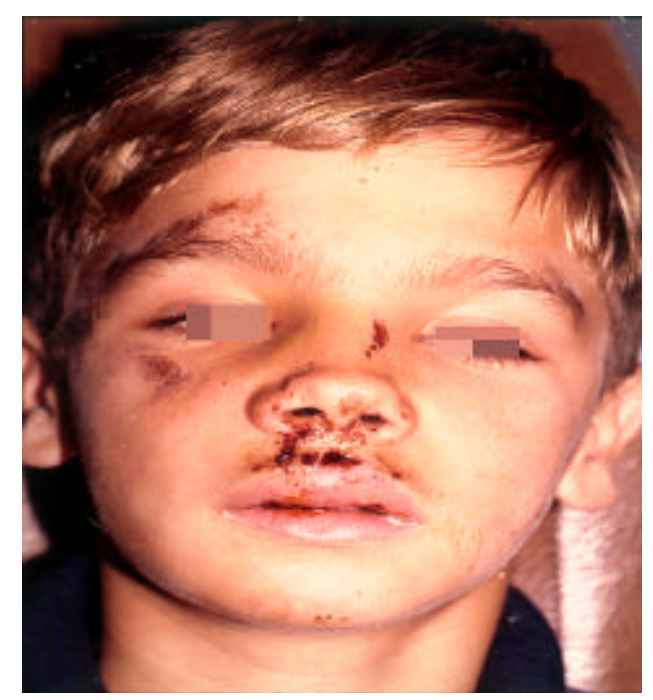

Fig. 2: Multiple extraoral injuries on the face of the 11 years old victim inflicted by abuser's hand

The familial violence and the ill treatment of children have been altered in one of the most recent social reflections. The dentists are part of the first line defense against the ill-treatment of children and adults in a lot of countries are compelled by the law to be educated on the clarification of cases of ill-treatment or neglect of children. Nevertheless the statistics show that only a small percentage of reports peri ill-treatment emanates from the dentists. There are two types of family violence:

- The child abuse

- Adult violence in the house or marital abuse Elder abuse

The studies show that the abuse/neglect of children is presented in $77 \%$ of families in which exists ill-treatment of adults (Sweet, 1996; Mouden, 1998). The Odont ological identification examination of a decedent is based on a comparison of the pre and postmortem dental characteristics of the individual based on the dental record. Documentation may involve written notes, photographs, radiographs and in some cases videotapes or audiotapes may be helpful (Vale, 1997). Domestic violence is epidemic in western society (Fig. 2). In US reported number is in excess of 3 (Wiese and Daro, 1995) million per year and studies have found that 50 and $70 \%$ of these perpetrators also abuse their children or those of their intimate partner (Kessman, 2000). Child abuse, intimate partner abuse and elder abuse victims often have signs of injury that are readily visible to dentists. Dentists have a moral and legal obligation to recognize and report suspected abuse (Gwinn et al., 2004; Mehra, 2004; Kenney, 2006). 
Child abuse: The medical profession's first involvement in child abuse historically begins in 1946 with Caffey, a pediatric radiologist who observed that children with subdural haematoma sometimes also exhibited abnormal changes in long bones, indicative of previous trauma (Cottone and Standish, 1982). The 1962 publication of The Battered-Child Syndrome by Kempe and colleagues publicized this eternal problem for humanity. In 1967, the American Dental Association (ADA) reported the first evidence that dentists were not able to identify child abuse. Within 5 years of the publication of The Battered-Child Syndrome, all 50 states in USA independently adopted child abuse reporting laws Prevent Abuse and Neglect through Dental Awareness (PANDA) was founded in 1992 sponsored by Delta Dental.

On 20 November 2000, The Prevention of Child Abuse Law was brought into effect (Cameron et al., 1966; Vale, 1997; Kenney, 2006). All members of dental team have a unique opportunity and legal obligation to assist in the struggle against child abuse. This special opportunity exists because a high proportion of abused children suffer injuries to the face and head including the oral and perioral regions.

Dentists should be aware that physical or sexual abuse may result in oral or dental injuries or conditions that sometimes can be confirmed by laboratory findings (Cottone and Standish, 1982; Vale, 1997). Furthermore, injuries inflicted by one's mouth or teeth may leave clues, regarding the timing and nature of the injury as well as the identity of the perpetrator. Dentists are encouraged to be knowledgeable about such findings and their significance and to meticulously observe and document them. When questions arise or when consultation is needed, a pediatric dentist or a dentist with formal training in forensic odontology can ensure appropriate testing, diagnosis and treatment (Sweet, 1996; Vale, 1997; Stavrianos and Metska, 2002; Stavrianos et al., 2005a, b; Kenney, 2006; Stavrianos et al., 2007; Silver and Souviron, 2009). Child abuse can take many forms:

- $\quad$ Physical abuse (the most usual form Fig. 2)

- Sexual abuse

- Mental injury-Emotional abuse

- Munchausen's syndrome by proxy (describes children that are victims of parentally fabricated or induced illness) (Gelles et al., 1987; Stavrianos and Metska, 2002; Herschaft et al., 2006).

It is important to realize that all dentists have a unique opportunity and ethical obligation to assist in the struggle against child abuse and that's because a high proportion of abused children suffer injuries to the face and head including the oral and peri-oral regions (Vale, 1997; Stavrianos et al., 2005a, b). A key step in recognizing and reporting abuse is conducting and documenting interviews with the child and parents. For reporting if the child requires medical attention referral should be made to the proper resource.

If the presence and appearance of the injury does not relate to the history of the injury and the explanation of its cause by both the child and the care-giver suspected abuse must be reported. Moreover, when certain injuries and conditions, fractures of bones in the absence of an adequate history, bitemarks, multiple of varying colours bruises or abrasions anywhere on the body of an infant, burns are observed then child abuse and neglect should be suspected (Sognnaes, 1978; Rothwell, 1995; Vale, 1996, 1997; Mouden and Kenney, 2005). Dentists must become more aware of their moral, legal, ethical responsibilities in recognizing, reporting child abuse and neglect (Gelles et al., 1987; Sweet, 1996; Tsang and Sweet, 1999; Mehra, 2004; Gwinn et al., 2004; Mouden and Kenney, 2005; Stavrianos et al., 2007). Usually these injuries will be bite marks inflicted upon the child.

The odontologist may have the opportunity to examine the child, living or deceased. More often the odontologist using supplied photographs is asked to give an opinion concerning the presence of bite marks and the quality as well as the origin of their infliction. Most of the times the quality of photos are is quite moderate as there is a great distance from the injury or the supplied photograph is out of focus or there is no scale (ruler). The fact is that a more quality photograph is taken by an experienced deontologist when he or she has the opportunity to see the child whether in the hospital ER, morgue, etc. (Vale, 1996; Herschaft et al., 2006). In case of bite marks infliction on a child's body, unless observed soon after the bite was inflicted, often present as a diffuse bruising of ovoid or elliptical shape with little or no definition of individual teeth (Spencer, 1995).

The Forensic Odontologist is the only one who can determine the origin of the bite mark if it was inflicted by an adult or young child. According to the reseachers forensic experience all the above information lead to the abuser and his admitting concerning his involvement with the child or to certain individuals who may have had access to the child.

Proper photography of patterned injuries (bite marks) in the physician's or dentist's office, the hospital emergency room or at the police station can be of a great aid in order to analyse and compare potentially the mark (s). It is quite natural some dentists to be concerned about 
whether or not should be involved in a case of suspected child abuse with one of their patients. It is urging that the dentist should report the suspected abuse. The dentists' role should not be the one of a detective as far as the abuse is concerned the suspected abuse. The proper authorities will be in charge of the investigation. Certainly there could be a potential for the dentist to give his testimony in future court proceedings. Under no circumstances must the dentist be involved or subjective concerning his testifying preventing him from making a report (Sweet, 1996; Vale, 1997; Kessman, 2000; Spencer, 2004; Mouden and Kenney, 2005; Kenney, 2006; Stavrianos et al., 2007; Silver and Souviron, 2009).

Intimate Partner Violence (IPV): Intimate partner violence is a dark phenomenon that exists for many years and tortures many families in the society. It refers to the expression of violence in the domestic boundaries. When in a couple either a heterosexual one or a homosexual, one of the two parties acts violently and assaults the other causing physical and psychological damage then legal measures should be taken and professional intervention must be asked from the victim or his/her environment (Fig. 3) (Cohen and Johnson, 2006; Thompson et al., 2006).

Usually intimate partner violence affects women because they are more vulnerable to abuse by their own nature. It is a fact, though that in the societies after the historical movements for the support of women rights and equality, it is not unusual for a woman to act violently and abusively in her relationships with men (Young et al., 1997; Coker et al., 2000; Goodman, 2006). Intimate partner violence includes:

- Acts of physical aggression

- Psychological abuse

- Forced inter-course and other forms of sexual coercion

- Various controlling behaviours such as isolating a person from his family

There are numerous expressions of the IPV syndrome but in most cases all ways of abuse finally appear at some point as the problem remains unsolved and left to expand at enormous dimensions. It may start with irritation and nervous behaviour by the intimate partner towards the victim and this is manifested by yelling being rude and abrupt, throwing out insults and uttering threats (Young et al., 1997; Cohen and Johnson, 2006). Since the victims are reluctant to collaborate with the authorities and report the abusive episodes, the clinical doctors and dentists that treat these women, need to be experienced and aware of signs that connect and relate the injuries with intentional and violent background

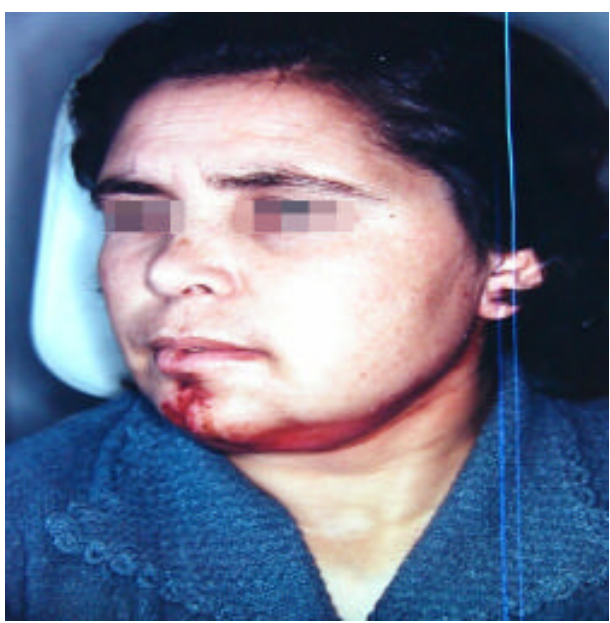

Fig. 3: Injuries and lesions on the chin. Patient was transferred to Hospital in the Department of Oral and Maxillofacial Surgery for the treatment of lesions that were the result of assaults and batteries of her husband

even though the patient insists on the accidental causing (Young et al., 1997; Tsang and Sweet, 1999; Mehra, 2004). Some of these indications are:

- Bruises found in different stages of healing. This imply of repeated assaults

- Bilateral injuries in the facial area that can't be the result of an accident of any kind

- Biting marks

- Lip lacerations and nasal injuries that were caused by fist

- Also the neck area is usually injured in cases of abuse

- Mandibular fractures

These signs combined with the peculiar and suspicious behaviour of the patient guide the doctor/dentist to suggest the possibility of domestic maltreatment by the intimate partner of the patient (Wiese and Daro, 1995; Thompson et al., 2006; Kenney, 2006; Silver and Souviron, 2009).

Elder abuse: The profile of an abuser of older individuals indicates that they are often the adult child spouse or caregiver of the older victim. Senior citizens can be abused/neglected in the following ways (physical abuse, sexual abuse, passive neglect, active neglect, self-neglect, material (financial) abuse and psychological abuse). As with younger victims of inflicted abusive trauma, the elderly can be victims of physical abuse that involves injuries to the maxillofacial complex. Intentional trauma to 
oral and paraoral structures can include lacerations and contusions of the lip trauma, fracture or subluxated teeth, fractures of the mandible or maxilla or severe bruising of the edentulous ridges. In addition to examining the victim for their immediate acute traumatic injuries the dentist should also examine attempt to identify indicators of prior trauma to the orofacial structures.

Oral manifestations of sexually transmissible diseases can be an indicator of sexual abuse of the elderly person (Coker et al., 2000; Glassman et al., 2004; Nelson et al., 2004; Nixon et al., 2004; Thompson et al., 2006; Kenney, 2006; Goodman, 2006). Moreover, biting activity is not rare in cases of elder abuse.

Forensic odontologists are often consulted to evaluate patterned injuries for possible bite mark evidence in these cases. In the end of this article procedures and protocols that are practiced in the U.S.A. concerning elderly individuals. Elder abuse can happen to any of environment. The dentistsare likely to be in contact with these individuals who have been exposed to this kind of violence. The dental team that is alert to the fact that many elderly or vulnerable person are abused, that many of these abused individuals have injuries to the head and around the mouth may be able to identify an abused person and institute steps that might save someone's life (Mayer and Galan, 1993; Sobsey and Mansell, 1994; Waalen et al., 2000; Wolf, 2002; McDowell, 2005; Corbett, 2005; Nerenberg, 2007). Dental practitioners have four R responsibility, they are recognize, report, refer to protect the patients and their families from the cycle of violence all to prevalent in society today (Kenney, 2006).

Contribution in anthropological and archaeological research: It is widespread known that the teeth and the bones of jaws are maintained very well in the passage of the centuries (Fig. 4). They constitute precious discoveries and source of information. With the help of other specialties (archaeology, anthropology, radiology) is demonstrated a completed picture of the ancient period that is studied (Morse et al., 1983).

The Forensic dentistry has some axes on the archaeology. These are examination and estimation of jaw and teeth discoveries that was found in archaeological excavations. The information by their study can help in the representation and comprehension of the archaeological period. Also, a major axe is the research in dental problems aiming at the improvement of knowledge and the promotion of Dental science (Whittaker and MacDonald, 1989; Stimpson and Mertz, 1997). Forensic Dentistry's contribution lies in:

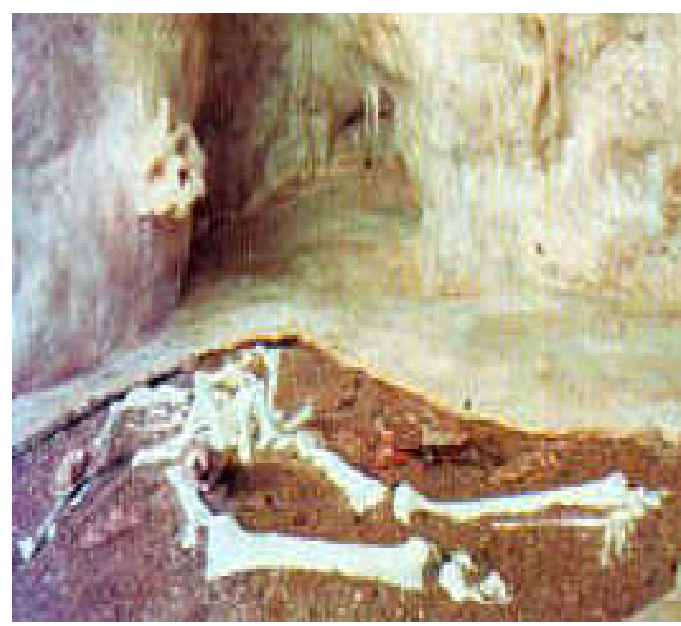

Fig. 4: Archanthropus of Trillia (11,000,000 B.C.), Greece

- The dated of discoveries

- The determination of age and identity

- The estimation of demographic team's size

- The study of dental and jaw diseases

- The benefit of information that represent the lifestyle and the behavior of ancient cultures

- The determination of alimentary habits

- The comprehension of the environment

- The investigation of criminal energies of antiquity

- The study of history and applications of dentistry

The methodology that is followed is the same with the methods that referred in identification passage. The forensic dentistry applications have some major problem in archaeology. The teeth are presenting erosion from the acids in the soil. The corpse is incinerated. The conditions of burial are likely to destroy the teeth (i.e., cover of coffin with plaster). The teeth are removed from the alveolar bone. Finally, the dentin and cementum of root are absorbed (Morse et al., 1983; Whittaker and MacDonald, 1989; Hochrein, 1997).

Attribution of urban responsibility: The Forensic dentis try enforces the field of urban and criminal cases and has as purpose the scientific expertise, the detection and solution of crime. The dentist will be called to deposit his scientific testimony in the room of court. The forensic doctor examines individual persons that they have been wounded from accident, problems of oral health because of neglect or incomplete dental care and last for the certification of dental works. The role of Forensic dentistry is to strengthen and help the enforcement of law (Cottone and Standish, 1982; Frazer, 1986; Barsley, 1993; Sweet et al., 1996; Katz and Cottone, 1988). 


\section{CONCLUSION}

The aim of the study is to show how important are for the society the applications of Forensic dentistry. As members of the dental profession, it should be realized that dentistry is a unique position to help society. Providing the proper training to the dentists, also give them the power to participate actively in a process that may help to save the lives of otherwise helpless children and elders to enforce the law to identify and to be in the first line of aid if there is appearance of mass disaster. The Forensic dentistry is still developing. The decipherment of DNA opens new roads to research and analyzing methods.

\section{REFERENCES}

Avon, L.S., 2004. Forensic odontology: The roles and responsibilities of the dentist. J. Can. Dental Assoc., 70: 453-458.

Barsley, E.R., 1993. The scope of forensic dentistry. Dental Clin. North Am., 13: 133-156.

Bowers, C.M. and G.L. Bell, 1995. Manual of Forensic Odontology. 3rd Edn., ABFO, Colorado Springs, pp: 299, 334-353.

Cameron, J.M., H.R. Johnson and F.E. Camps, 1966. The battered child syndrome. Med. Sci. Law, 6: 2-21.

Cohen, P. and J.G. Johnson, 2006. Development of personality disorder symptoms and the risk for partner violence. J. Abnormal Psychol., 115: 474-483.

Coker, A.L., P.H. Smith, L. Bethea, M.R. King and R.E. Mckeown, 2000. Physical health consequences of physical and psychological intimate partner violence. Arch. Fam Med., 9: 451-457.

Corbett, A.P., 2005. Case study of potential elder abuse. J. Forensic Nurs., 1: 182-186.

Cottone, J.A. and S.M. Standish, 1982. Outline of Forensic Dentistry. Year Book Medical Publishers, Chicago.

Dorion, R.B.J., 2005. Bite Mark Evidence (Electronic Resource). Marcel Dekker, New York.

Frazer, M., 1986. Domestic violence: A medico legal review. J. Forensic Sci., 31: 1409-1419.

Furness, J., 1981. A general review of bite mark evidence. Am. J. Forensic Pathol., 2: 49-52.

Gelles, R.J., R. Hampton, T. Gullota, G. Adams, E. Potter and R. Weissberg, 1987. Family Violence: Prevention and Treatment. Sage Publications Inc., Newbury Park, pp: $1-20$.

Glassman, P.D., E.M. Chavez and D. Hawks, 2004. Abuse and neglect of elderly individuals: Guidelines for oral health professionals. J. California Dental Assoc., 32: $323-335$.
Goodman, P.E., 2006. The relationship between intimate partner violence and other forms of family and societal violence. Emergency Med. Clin. North Am., 24: 889-903.

Gwinn, C., G.E. McClane, K.A. Shanel-Hogan and B.G. Strack, 2004. Domestic violence: No place for a smile. J. California Dental Assoc., 32: 399-407.

Herschaft, E., M. Alder, D. Ord, R. Rawson and E. Smith, 2006. Manual of Forensic Odontology. ASFO, Impress Printing and Graphics Inc., New York, pp: $210-240$.

Hochrein, J.M., 1997. Buried Crime Scene Evidence: The Application of Forensic Geotaphonomy in Forensic Archaeology. In: Forensic Dentistry, Stimpsons, P.G. and C.A. Mertz (Eds.). CRC Press, Boca Raton, Florida, pp: 83-99.

Katz, J.O. and J.A. Cottone, 1988. The present direction of research in forensic dentistry. Forensic Sci., 33: $1319-1327$.

Kenney, P.J., 2006. Domestic violence: A complex health care issue for dentistry today. Forensic Sci. Int. 159: 121-125.

Kessman, J., 2000. Domestic violence: Identifying the deadly silence. Texas Dental J., 117: 42-47.

Mayer, L. and D. Galan, 1993. Elder abuse and dentists' awareness and knowledge of the problem-a national survey. J. Can. Dental Assoc., 59: 921-926.

McDowell, J.D., 2005. Role of Health Professionals in Diagnosing Patterned Injuries from Birth to Death. Marcel Decker Publishers, New York, pp: 31-43.

Mehra, V., 2004. Culturally competent responses for identifying and responding to domestic violence in dental care settings. J. California Dental Assoc., 32: 387-395.

Morse, D., J. Duncan and J. Stoutamire, 1983. Handbook of Forensic Archaeology and Anthropology. Florida State University Foundation, Tallahassee FL, pp: $39-52$.

Mouden, L.D. and P.J. Kenney, 2005. Oral Injuries. In: Child Maltreatment: A Comprehensive Photographic Reference Identifying Potential Child Abuse, GW Medical Publishing, St. Louis, pp: 395-397.

Mouden, L.D., 1998. The role for dental professionals in preventing child abuse and neglect. J. California Dental Assoc., 26: 737-737.

Nelson, H.D., P. Nygren, Y. Mclnerney and J. Klein, 2004. Screening women and elderly adults for family and intimate partner violence: A review of the evidence for the U.S. preventive services task force. Ann. Inter. Med., 140: 387-396.

Nerenberg, L., 2007. Elder Abuse, Prevention. Springer Publishing Co., New York. 
Nixon, R.D., P.A. Resick and P. Nishith, 2004. An exploration of comorbid depression among female victims of intimate partner violence with posttraumatic stress disorder. J. Affective Disorder, 82: $315-320$.

Pretty, I.A. and D. Sweet, 2001. The scientific bases for human bite mark analysis-a critical review. Sci. Justice, 41: 85-92.

Rothwell, B.R., 1995. Bitemarks in forensic dentistry: A review of legal and scientific issues. J. Am. Dental Assoc., 126: 223-232.

Silver, E.W. and R.R. Souviron, 2009. Dental Autopsy. CRC Press, Florida, pp: 75-180.

Sobsey, D. and S. Mansell, 1994. An international perspective on patterns of sexual assault and abuse of people with disabilities. Int. J. Adolescent Med. Health, 7: 153-178.

Sognnaes, R.F., 1978. Forensic Science and Oral Biology. W.B. Saunders Co., Toronto, pp: 1155.

Spencer, D.E., 1995. Bite Marks in Child Abuse: Manual of Forensic Odontology. 3rd Edn., Printing Specialists, Montpelier VT, pp: 78.

Spencer, E.D., 2004. Child abuse: Dentists' recognition and involvement. J. California Dental Assoc., 32: 299-303.

Stavrianos, C. and M.E. Metska, 2002. Child abuse and neglect. Dental and Forensic Dental Aspect. Thessaloniki, pp: 27-30.

Stavrianos, C., D. Mastagas and P. Stavrianou, 2005a. The responsibility of dentist's in identifying and reporting child abuse. Internet J. Law Healthcare Ethics, 5: 1-18.

Stavrianos, C., M.E. Metska and N. Petalotis, 2005b. Child abuse: It's recognition by dentists. Balkan J. Stomatol., 9: 204-207.

Stavrianos, C., L. Zouloumis, O. Karaiskou and I. Stavrianou, 2007. Family violence and child abuse. Balkan J. Stomatol., 11: 13-20.

Stimpson, P.G. and C.A. Mertz, 1997. Forensic Dentistry. CRC Press, Boca Raton, Florida.
Sweet, D. and D.P. Hildebrand, 1999. Saliva from cheese bite yields DNA profile of burglar: A case report. Int. J. Legal Med., 112: 201-203.

Sweet, D.J., 1996. Recognizing and intervening in domestic violence: Proactive role for dentistry. Medscape Women's Health, 1: 3-3.

Sweet, D.J., S. Kashani, K. Leavitt, T. Manji, V. Miao-Wan and N. Peeters, 1996. Forensic dentistry: A review of its scope and application. J. Can. Soc. Forensic Sci., 29: 143-153.

Thompson, R.S., A.E. Bonomi, M. Anderson, R.J. Reid, J.A. Dimer, D. Carrell and F.P. Rivara, 2006. Intimate partner violence: Prevalence, types and chronicity in adult women. Am. J. Prev. Med., 30: 447-457.

Tsang, A. and D.J. Sweet, 1999. Dentistry's role in child abuse and neglect-Are we doing enough? J. Can. Dental Assoc., 65: 387-391.

Vale, G.L., 1996. Dentistry, bitemarks and the investigation of crime. J. California Dental Assoc., 24: 29-34.

Vale, G.L., 1997. Dentistry's Role in Detecting and Preventing Child Abuse. In: Forensic Dentistry, Stimson, P.G. and C.A. Mertz (Eds.). 1st Edn., CRC Press, Boca Raton, NY., pp: 161-162.

Waalen, J., M.M. Goodwin, A.M. Spitz, R. Petersen and L.E. Saltzman, 2000. Screening for intimate partner violence by health care providers: Barriers and interventions. Am. J. Preventive Med., 19: 230-237.

Whittaker, D.K. and D.G. MacDonald, 1989. A Colour Atlas of Forensic Dentistry. Wolfe Medical Publications Ltd., London.

Wiese, D. and D. Daro, 1995. Current trends in reporting and fatalities of the 1994 annual 50 state survey. National Committee to Prevent Child Abuse, Working Paper No. 808.

Wolf, R., 2002. Elder Abuse and Neglect: History and Concepts. The National Academies, America, pp: $238-246$.

Young, M.E., M.A. Nosek, C. Howland, G. Chanpong and D.H. Rintala, 1997. Prevalence of abuse of women with physical disabilities. Arch. Phys. Med. Rehabil., 78: 34-38. 